\title{
Compliance with CPAP in patients with obstructive sleep apnea
}

\section{Short Communication}

Obstructive Sleep Apnea (OSA) is characterized by repetitive episodes of partial or complete upper airway obstruction during sleep. OSA may cause several consequences, including daytime sleepiness, non-restorative sleep, and heart disease or metabolic syndrome associated with a sleep AHI $>5 \mathrm{ev} / \mathrm{h}$. Based on available general population-based studies, the prevalence of obstructive sleep apnea (OSA) associated with accompanying daytime sleepiness is approximately $11 \%$ for adult men and $4 \%$ for adult women.

Patients with obstructive sleep apnea usually consult for symptoms such as habitual or loud snoring, apneas, tiredness or fatigue, and excessive daytime sleepiness. Sometimes, the initial complaints are nonspecific symptoms such as insomnia, frequent awakenings at night, nocturia, morning headaches, or neurocognitive impairment. ${ }^{2}$

Continuous positive airway pressure (CPAP) is currently the treatment of choice for patients with obstructive sleep apnea (OSA). Although it is a highly effective treatment, compliance with therapy remains a difficult issue. Many previous studies that have addressed this subject have evaluated compliance over relatively brief periods of time (one to six months). ${ }^{3-5}$

Long-term studies are far fewer and studies assessing compliance years after diagnosis are rare. ${ }^{6,7}$ In these reports, the reasons for noncompliance have often been inadequately documented. Moreover, compliance may have been overestimated in some because only those patients who actually embarked on CPAP therapy were included. Some patients who are prescribed CPAP may not obtain the device and are therefore not included in any subsequent analysis of compliance.

Our team have found that the mask problems, use time less than one year and non positive impact of CPAP on the pre-treatment snoring are factors directly associated with low compliance of CPAP treatment, in term of diary time use less than 5 hours per night and less than 4 nights per week. ${ }^{8}$

It has been estimated that approximately $25 \%$ of all patients with OSA discontinue therapy in long-term follow-up ${ }^{9}$. The resultant rate would be more than $75 \%$, a value similar to that noted by others. ${ }^{9-12}$

Many authors have attempted to use demographic data or initial laboratory results in an effort to predict subsequent CPAP compliance. Age, sex and OSA severity, as judged by the AHI or CPAP pressure requirement could not be used to predict subsequent CPAP use.

While some studies, ${ }^{13}$ have noted similar results, others, ${ }^{14}$ have found that CPAP compliance does correlate with the initial AHI. The results for age and sex have similarly been inconsistent. The impact of OSA on the patient, namely sleepiness, has been consistently mentioned as one of the best pretreatment predictors of long-term CPAP use. ${ }^{8,15,16}$

Improvement in sleep even during the initial CPAP titration has also been found to be important in predicting the subsequent use of this treatment modality. ${ }^{17}$
Volume 6 Issue 3 - 2019

Codinardo Carlos

Chief of Pneumonology Service, Argentina

Correspondence: Codinardo Carlos M.D, Chief of

Pneumonology Service, In charge of a Pneumonology Service at

a Hospital in Buenos Aires city, Argentina,

Email codinardo72@yahoo.com.ar

Received: May 28, 2019 | Published: June 27, 2019

Sin et al found that CPAP use correlated with age and female sex. However, Pelletier-Fleury et al, after controlling for confounding variables, found no independent effect of age and that female OSA patients were less compliant with CPAP therapy than male OSA patients. ${ }^{18,19}$

However, many authors found that an optimal compliance will require periodic follow-up and effective interventions. ${ }^{20-22}$

The guidelines published, as American Academy of Sleep Medicine and the Canadian Thoracic Society, ${ }^{23}$ pointed out the value of initial control at first month after CPAP treatment prescribed, measuring average diary time of use and pressure used.

There are several technical approaches for increasing the confort parameters, focused about pressure CPAP tolerance. For example, using automatic pressure machines, named APAP, or bilevel machines (BiPAP), and recently CPAP with release of espiratory pressure (C-Flex method). ${ }^{24}$

However, they cannot demonstrate better compliance after use of the kind of technology.

Some authors recommend consider suitable compliance with CPAP, when the patient uses CPAP at least 5 (five) hours per day, 5 (five) nights per week, with positive clinical impacto n symptoms without relevants colateral effects. ${ }^{11}$

Between measures that contributes to improve CPAP compliance there are better development of new masks, reducing the abandon of CPAP during the first weeks of therapy

Now, new models, with better comfortable and adapted masks to facial shape, reducing pressure lose and pressure required. Suitable cleanning contributes to reduce the incidence of infections respiratory diseases linked to CPAP users.

Moderate-quality evidence shows that a short-term educational intervention results in a modest increase in CPAP usage. Low-quality evidence indicates that behavioral therapy leads to a large increase in CPAP machine usage. The impact of improved CPAP usage on daytime sleepiness, quality of life and long-term cardiovascular risks remains unclear. For outcomes reflecting machine usage, we downgraded for risk of bias and inconsistency. An additional limitation for daytime 
sleepiness and quality of life measures was imprecision. Trials in people who have struggled to persist with treatment are needed, as currently little evidence is available for this population. Optimal timing and duration and long-term effectiveness of interventions remain uncertain. ${ }^{24-27}$

\section{Final comments}

Although many patients with OSA derive subjective benefit from, and adhere to treatment with CPAP, a significant proportion of those diagnosed either does not initiate or eventually abandon therapy. Initial experience with CPAP appears to be important, reinforcing the need for early education and support in these patients.

\section{Acknowledgements}

None.

\section{Conflicts of interest}

Author declares that there is no conflict of interest.

\section{References}

1. Peppard PE, Young T, Barnet JH, et al. Increased prevalence of sleepdisordered breathing in adults. Am J Epidemiol. 2013;177(9):1006-1014

2. Definición y concepto, fisiopatología, clínica y exploración del SAHS Consenso Nacional sobre el Síndrome Apneas-Hipopneas del Sueño del Grupo Español de Sueño. Arch bronconeumol. 2005;41(4):12-29.

3. Pépin JL, Krieger J, Rodenstein D, et al. Effective compliance during the first 3 months of continuous positive airway pressure. American Journal of Respiratory and Critical Care Medicine. 1999;160(4):1124-1129.

4. Stepnowsky CJ, Jr, Marler MR, Ancoli-Israel S. Determinants of nasal CPAP compliance. Sleep Medicine.2002;3(3):239-47.

5. Wilk MR, Engleman HM, Douglas NJ, et al. Can psychological factors help us to determine adherence to CPAP? A prospective study. Eur Respir J. 2004;24:461-465.

6. Sucena M, Liistro G, Aubert G, et al. Continuous positive airway pressure treatment for sleep apnoea: Compliance increases with time in continuing users. European Respiratory Journal. 2006;27:761-766.

7. Bizieux-Thamin A, Gagnadoux F, Binquet C, et al. Long term use of nCPAP therapy in sleep apnoea patients. Revue des Maladies Respiratoires. 2006;22:951-957.

8. Codinardo C. Compliance with continuos positive airway pressure in patients with sleep apnea/hypopnea syndrome. ERS Congress oral presentation.

9. de Zeeuw J, Baberg HT, Duchna HW, et al. Locus of control belief is a predictor of CPAP-compliance in patients with obstructive sleep apnea syndrome. Pneumologie. 2007;61:283-90.

10. Bizieux-Thamin A, Gagnadoux F, Binquet C, et al. Long term use of nCPAP therapy in sleep apnoea patients. Rev Mal Respir. 2005;22:951957.

11. Engleman HM, Martin SE. Compliance with CPAP therapy in patients with sleep apnea/ hipopnea syndrome. Thorax. 1994;49(3):263-6.
12. McArdle N, Devereux G, Heidarnejad H, et al. Long-term use of CPAP therapy for sleep apnea/hypopnea syndrome. Am J Respir Crit Care Med. 1999;159(4):1108-14.

13. Sucena M, Liistro G, Aubert G, et al. Continuous positive airway pressure treatment for sleep apnoea: Compliance increases with time in continuing users. Eur Respir J. 2006;27:761-766.

14. McArdle N, Devereux G, Heidarnejad H, Engleman HM, Mackay TW, Douglas NJ. Long-term use of CPAP therapy for sleep apnea/hypopnea syndrome. Am J Respir Crit Care Med. 1999;159:1108-1114.

15. Rauscher H, Popp W, Wanke T, Zwick H. Acceptance of CPAP therapy for sleep apnea. Chest. 1991;100(4):1019-1023.

16. Engleman HM, Asgari-Jirhandeh N, McLeod AL, et al. Self-reported use of CPAP and benefits of CPAP therapy: A patient survey. Chest. 1996;109:1470-1476.

17. Drake CL, Day R, Hudgel D, et al. Sleep during titration predicts continuous positive airway pressure compliance. Sleep. 2003;26(3):30811.

18. Sin DD, Mayers I, Man GC, Pawluk L. Long-term compliance rates to continuous positive airway pressure in obstructive sleep apnea: A population-based study. Chest. 2002;121:430-435.

19. Pelletier-Fleury N, Rakotonanahary D, Fleury B. The age and other factors in the evaluation of compliance with nasal continuous positive airway pressure for obstructive sleep apnea syndrome. A Cox's proportional hazard analysis. Sleep Med. 2001;2(3):225-232.

20. Meurice J, Dore P, Paquereau J, et al. Predictive factors of long-term compliance with nasal continuous positive airway pressure treatment in sleep apnea syndrome. Chest. 1994;105(2):429-33.

21. Gallego C, Dibur E. Salomone C. Di Bartolo C. Adherencia al tratamiento con presión positiva continua nasal en pacientes con SAHOS. Medicina Buenos Aires. 2004;64:395-399.

22. Damjanovic, A. Fluck, H. Bremer, et al. Compliance in sleep apnoea therapy: influence of home care support and pressure mode D. Eur Respir J. 2009;33:804-811.

23. Fleetham J, Ayas N, Bradley D, et al. Canadian Thoracic Society guidelines: diagnosis and treatment of sleep disorderedbreathing in adults. Can Respir J. 2006;13:387-92.

24. Ayas NT, Patel SR, Malhotra A, et al. Auto-titrating versus standard continuous positive airway pressure for the treatment of obstructive sleep apnea: results of a meta-analysis. Sleep. 2004;27(2):249-253.

25. Sala H, Nigro C, Rabec C, et al. Consenso Argentino de Trastornos Respiratorios Del Sueño. MEDICINA (Buenos Aires). 2001;61:351-363.

26. Nogueira F y cols Guias pràcticas de diagnòstico y tratamiento del síndrome de apneas e hipopneas obstructivas del sueño. MEDICINA (Buenos Aires). 2013;73:349-362.

27. Kushida CA, Littner MR, Hirshkowitz M, et al. Practice parameters for the use of continuous and bilevel positive airway pressuredevices to treat adult patients with sleep-related breathing disorders. Sleep . 2006;29(3):375-380 